shortcoming of time-averaged estimates is that they do not really predict radiological outcome.

Objectives To investigate, using multivariate longitudinal regression analysis, whether disease activity can predict radiological progression with a fixed time lag of 6 months.

Methods 5 years follow-up data of RA-patients having participated in the COBRA trial (a 56-weeks double blind controlled trial in 146 patients with early, DMARD-naive, RA which compared COBRA-combination therapy with sulfasalazine monotherapy) were used. After the completion of the trial, patients had been followed for another 4 years, and X-rays of hands and feet, as well as assessments for disease activity, were obtained with 6 months intervals. X-rays were scored according to the van der Heijde-modified Sharp-method in a chronological order. The 28 joints disease activity score (DAS28) was calculated. Generalised estimating equations (GEE) was used to study the relationship between DAS28 and time (explanatory variables) and radiological damage (dependent variable). Every individual damage score was adjusted for its previous score (6 months earlier) (autoregression) in order to study radiological

Results The interpretation of the beta's in the Table 1 is that each additional DAS2 8 point, measured at any time point, predicts a mean radiological progression of 0.52 Sharp-points during the following 6 months interval. The negative sign for time indicates that radiological progression in this study decreased over time.

\begin{tabular}{llll}
\multicolumn{4}{l}{ Abstract THU0152 Table 1} \\
\hline & Beta & $95 \%$ Cl & P-value \\
\hline Time & -1.02 & -1.80 to -0.24 & 0.01 \\
DAS28 (6 m. earlier) & 0.52 & 0.20 to 0.68 & 0.001 \\
\hline
\end{tabular}

Conclusion By using GEE we have shown that DAS measured at any time point during a 5 years follow-up predicts radiological progression during the following 6 months. GEE is an appropriate method to study longitudinal relationships between outcomeand explanatory variables in RA.

\section{THU0153 OPEN-LABEL EVALUATION OF THE QUALITY OF LIFE OF PATIENTS TREATED WITH ETANERCEPT IN COMMON RHEUMATOLOGY USAGE (ECRU)}

1J Hermann, ${ }^{2} \mathrm{~A}$ Aytekin, ${ }^{3} \mathrm{~J}$ Bröll, ${ }^{4} \mathrm{~A}$ Dunky, ${ }^{2} \mathrm{~J}$ Nowak, ${ }^{5} \mathrm{~F}$ Singer, ${ }^{6} \mathrm{~J}$ Smolen. ${ }^{1} \mathrm{Med}$. Department LKH, Graz; ${ }^{2}$ Med. Department, Wyeht Lederle, Wien; ${ }^{3}$ 2. Med. Department, KFJ, Wien; ${ }^{4} 5$. Med. Department, Wilheminenspital, Wien; ${ }^{5}$ SKA, Laab Im Walde; ${ }^{6}$ Int. Med. III, AHK, Wien, Austria

\subsection{6/annrheumdis-2001.1055}

Background Tumour Necrosis Factor-alpha (TNF $\alpha$ ) plays an important role in the inflammatory processes of RA and the resulting joint pathology. Etanercept is a dimeric fusion protein consisting of two p75 TNF $\alpha$ receptors linked to the Fc portion of the human IgG1. This protein can bind and inactivate up to two free molecules of TNF $\alpha$. The safety and efficacy of etanercept has been demonstrated in human clinical trials of early RA and active RA.

Objectives This current study was designed to further evaluate safety and efficacy of etanercept. One of the objectives was also to evaluate quality of life of patients treated with this substance by means of SF-36.
Methods This study was conducted in 55 Austrian outpatients with active RA who have failed at least one disease-modifying anti-rheumatic drug (DMARD). Each patient received twiceweekly subcutaneous injections of etanercept $25 \mathrm{mg}$ administered over a treatment period of 16 weeks. Stable doses of methotrexate (MTX) and steroids were permitted. For SF-36 interpretation the normal rages of the most recent published Canadian data and SF-36 Manual were used.

Results At baseline, all 8 domains revealed substantially lower score than observed in healthy subjects. Five of them indicated level of disability of $50 \%$ or more.

At week 16, all domains improved. Observed improvements ranged from 15 (general health perceptions) to 42,1 points (role function limited by physical problems). All were clinically significant (more than 5 points improvement). Two domains reached almost level characteristic for a healthy population: social functioning (97\% of normal) and mental health (92\% of normal).

\section{Conclusion}

- In general, study patients at baseline demonstrated poor functioning in all domains of SF-36 QoL assessment; in five domains their functioning was at least $50 \%$ worse than in healthy subjects.

- The study was conducted in a heavily pretreated population. In spite of that, substantial improvement in the course of the study was observed.

- Improvement in all domains could be observed already after one week of treatment. At week 16, substantial improvement in all 8 domains was recorded, in two of them reaching almost normal ranges.

- The significant improvement in Physical Function and Bodily Pain also suggest that work-difficulty may be delayed or prevented in patients treated with etanercept.

\section{THU0154 ATLANTOAXIAL DISORDERS IN RHEUMATOID ARTHRITIS ASSOCIATE WITH DESTRUCTIONS OF THE PERIPHERAL AND SHOULDER JOINTS, AND DECREASED BONE MINERAL DENSITY}

${ }^{1} \mathrm{MH}$ Neva, ${ }^{2} \mathrm{~A}$ Kotaniemi, ${ }^{2} \mathrm{~K}$ Kaarela, ${ }^{3} \mathrm{JT}$ Lehtinen, ${ }^{2} \mathrm{P}$ Isomäki, ${ }^{3} \mathrm{EA}$ Belt, ${ }^{2} \mathrm{H}$ Kautiainen, ${ }^{2} \mathrm{M}$ Kauppi. 'Department of Surgery, Tampere University Hospital, Tampere; ${ }^{2}$ Department of Rheumatology; ${ }^{3}$ Department of Orthopaedic Surgery, Rheumatism Foundation Hospital, Heinola, Finland

\subsection{6/annrheumdis-2001.1056}

Background Anterior atlantoaxial subluxation (aAAS) and atlantoaxial impaction (AAI) are common cervical spine disorders in advanced rheumatoid arthritis (RA;1). Earlier studies have suggested the association of the cervical spine disorders with peripheral joint destruction and osteoporosis of the cervical spine.

Objectives To evaluate whether atlantoaxial disorders (aAAS and $\mathrm{AAI}$ ) associate with destruction of shoulder- (glenohumeral [GH] or acromioclavicular $[\mathrm{AC}]$ ) or peripheral joints, and bone mineral density (BMD) in patients who have suffered RA for 20years.

Methods An inception cohort of 103 patients with rheumatoid factor (RF) positive RA were followed up for 20 years, a total of 68 patients attended the 20 -year check-up. ${ }^{1}$ The shoulder radiographs were taken at the 15 -year examination, and the cervical spine, hand and foot radiographs at the 20-year follow-up. Moreover, the BMD of the lumbar spine and femoral neck were measured at the 20-year check-up. Thereafter, the occurrence and severity of atlantoaxial disorders were compared with the Larsen scores of peripheral and shoulder (GH and AC) joints, and with BMD of the lumbar spine and femoral neck. 